\title{
A Study on the Learning Situation for Basic Mathematics Master Students
}

\author{
Hailun Fu, Qi Gao, Chunjie Yu \\ School of Mathematics and Statistics, Shandong Normal University, Jinan, China \\ Email: dubujinghong@163.com
}

How to cite this paper: Fu, H.L., Gao, Q. and Yu, C.J. (2017) A Study on the Learning Situation for Basic Mathematics Master Students. Open Journal of Social Sciences, 5, 202-213.

https://doi.org/10.4236/jss.2017.56018

Received: May 27, 2017

Accepted: June 19, 2017

Published: June 22, 2017

Copyright $\odot 2017$ by authors and Scientific Research Publishing Inc. This work is licensed under the Creative Commons Attribution International License (CC BY 4.0).

http://creativecommons.org/licenses/by/4.0/

\begin{abstract}
Graduate students are an essential part of the national high quality talents, and their learning situation is closely related with the development of the whole world. As a result, we argue that it is of vital importance to study the current situation of them. To understand the learning situation of basic mathematics master students, we have performed a deep investigation. In this paper, we first classify the study into two categories, i.e., study in class and study after class. Then we further refine them into 10 fine-grained aspects. Finally, we explain the conclusions that we find for master student of different categories.
\end{abstract}

\section{Keywords}

Learning Situation, Basic Mathematics, Learning Enthusiasm

\section{Introduction}

\subsection{Background}

With the development of the society, the demand for talents is gradually increasing. As an indispensable member of the state, the current situation of graduate study is closely related to the development of the whole world. To cultivate more talented students for the development of our society, the first thing we have to do is to understand their current situation. As mathematics is a discipline with strong and rigorous logic as well as a wide range of applications, its development will inevitably affects the development of society [1]. Therefore, it is important to study the current situation of the basic mathematics major. It should be clear that there are large bodies of evidence from a lot of various fields supporting it [2] [3] [4] [5]. Now we will perform a questionnaire analysis to explore the situation of the basic mathematics major. 


\subsection{Significance of the Study}

As we often say, the major contributor to society's stunning ignorance of science has been our educational system [6]. Generally speaking, mathematics has three basic characteristics: strictness, abstractness and universality. Due to the characteristics of mathematical learning and the influence of the students' own development level, each student's learning situation is typically different. There are some studies on the learning situation for basic mathematics master students [7] [8] [9]. It is meaningful to study the situation of master students. Firstly, it has a positive impact on the formation of good learning habits. Secondly, it can help improve academic performance and promote the healthy development of students. In addition, it is also helpful to enrich the vacancy of the relevant theories and it plays a positive role in the development and perfection of mathematical education psychology and social psychology [10].

\section{Process of the Study}

\subsection{Problem Analysis}

Narrow learning refers to the process of acquiring knowledge or skills through reading, listening and research, which is a way of making the individual to get a continuous change.

To understand the current learning situation of basic mathematics majors, we classified the study into two categories: in-class study and after-class study. The former can be refined into 5 aspects: listen to the class (LC), answer questions (AQ), do classroom exercises (DCE), discuss in class (DIC) and teach as a teacher (TAT). The latter can be divided into 5 aspects: do homework (DH), read materials (RM), review lessons (RL), preview lessons (PL) and discuss after class (DAC).

\subsection{Questionnaire Development}

According to the above analysis, we conduct a questionnaire containing 24 single topics, with the first 12 as a group, to examine the situation of studying in class, and the latter 12 questions as a group, to investigate the situation of studying after class (Table 1 and Table 2). For studying in class, the topics are divided into five groups: 1 to 3 as a group, 4 and 5 as a group, 6 and 7 as a group, $8,9,10$ as a group individually, 11 and 12 as a group, which corresponds to each sub-catalogues. For studying after class, the topics will also be divided into 5 groups: 13 to 15 as a group, to examine the situation of doing homework. 16 and 17 as a group, to examine the situation of reading materials. 18 to 20 as a group, to examine the situation of reviewing lessons. Question 21 to 22 as a group, to examine the situation of preview lessons. Question 23 and 24 as a group, to examine the situation of discussing after class. Each question has 5 answers. (see Appendix for the questionnaire).

\subsection{Distribution and Collection of Questionnaires}

After the completion of the questionnaire, they were distributed to each of the 
Table 1. Questions of studying in class and sub-catalogues.

\begin{tabular}{cc}
\hline Question & Sub-catalogues \\
\hline $1,2,3$ & LC \\
4,5 & AQ \\
6,7 & DCE \\
$8,9,10$ & DIC \\
11,12 & TAT \\
\hline
\end{tabular}

Table 2. Questions of studying after class and sub-catalogues.

\begin{tabular}{cc}
\hline Question & Sub-catalogues \\
\hline $13,14,15$ & $\mathrm{DH}$ \\
16,17 & $\mathrm{RM}$ \\
$18,19,20$ & $\mathrm{RL}$ \\
21,22 & $\mathrm{PL}$ \\
23,24 & $\mathrm{DAC}$ \\
\hline
\end{tabular}

graduate students in the basic mathematics of Shandong Normal University. They finished the questionnaire in 30 minutes. A total of 15 questionnaires were distributed and 15 valid questionnaires were returned.

\section{Conclusions}

\subsection{Results of the Study}

After collecting the questionnaire, the data was calculated. The process was as follows: Firstly, each student's answer was completed in the table. Then recording the number of each option and the proportion of each option. Next analyzing the proportion of each topic. Finally we drew conclusions of each topic. The findings of the questionnaire were as follows:

\subsubsection{Internal Causes}

1) Most of the students are careful to listen and take notes in class, but it is still difficult to understand the knowledge of professional courses.

Table 3 shows the number and percentage of questions 1, 2 and 3. From the first question, we can conclude that $53.34 \%$ of students are listening carefully more than 30 minutes each class. From the second question, we can conclude that $93.33 \%$ of students feel it difficult to understand the knowledge of professional courses. From the third question, we can conclude that $73.33 \%$ of the students take notes frequently. In conclusion, we can get that most of the students are careful to listen and take notes in class, but it is still difficult to understand the knowledge of professional courses.

2) Most of the students are positively in answering questions and they can listen to the other students carefully.

Table 4 shows the number and percentage of questions 4 and 5. From the 
Table 3. Number and percentage of questions $1,2,3$.

\begin{tabular}{ccccccccccc}
\hline \multirow{2}{*}{ Question } & \multicolumn{2}{c}{ A } & \multicolumn{2}{c}{ B } & \multicolumn{2}{c}{ C } & \multicolumn{2}{c}{ D } & \multicolumn{2}{c}{$\mathrm{E}$} \\
\cline { 2 - 10 } & No. & p.c. (\%) & No. & p.c. (\%) & No. & p.c. (\%) & No. & p.c. (\%) & No. & p.c. (\%) \\
\hline 1 & 2 & 13.33 & 0 & 0 & 5 & 33.33 & 7 & 46.67 & 1 & 6.67 \\
2 & 0 & 0 & 6 & 40 & 8 & 53.33 & 1 & 6.67 & 0 & 0 \\
3 & 0 & 0 & 1 & 6.67 & 3 & 20 & 5 & 33.33 & 6 & 40 \\
\hline
\end{tabular}

Table 4. Number and percentage of questions 4, 5 .

\begin{tabular}{ccccccccccc}
\hline \multirow{2}{*}{ Question } & \multicolumn{2}{c}{ A } & \multicolumn{2}{c}{ B } & \multicolumn{2}{c}{ C } & \multicolumn{2}{c}{ D } & \multicolumn{2}{c}{ E } \\
\cline { 2 - 10 } & No. & p.c. (\%) & No. & p.c. (\%) & No. & p.c. (\%) & No. & p.c. (\%) & No. & p.c. (\%) \\
\hline 4 & 2 & 13.33 & 3 & 20 & 6 & 40 & 3 & 20 & 1 & 6.67 \\
5 & 2 & 13.33 & 7 & 46.67 & 5 & 33.33 & 0 & 0 & 1 & 6.67 \\
\hline
\end{tabular}

fourth question, we can conclude that most of the students are quite active in the professional lessons. From the fifth question, we can conclude that $93.33 \%$ of the students can listen to the other students carefully. To sum up, most of the students are positively in answering questions and they can listen to the other students carefully.

3) Most of the students can think seriously about classroom exercises and they are satisfied with their completion.

Table 5 shows the number and percentage of questions 6 and 7. From the sixth question, we can conclude that most students can think seriously about the problems or practice given by teachers in the professional class. From the seventh question, we can conclude that $73.33 \%$ of students are satisfied with their completion. In conclusion, we can get that most of the students can think seriously about classroom exercises and they are satisfied with their completion.

4) Most of the students are quite active in the discussion, but only a few people can answer questions for other students.

Table 6 shows the number and percentage of questions 8, 9 and 10. From the eighth question, we can conclude that only a few people can answer questions for other students. From the ninth question, we can conclude that most students will participate in the discussion on a professional course. From the tenth question, we can conclude that most students will participate in the discussion actively when they are on a professional course. In summary, we can conclude that most of the students are quite active in the discussion, but only a few people can answer questions for other students.

5) Most of the students have the chance to teach as a teacher, but only a few can get out of the textbook when they do it.

Table 7 shows the number and percentage of questions 11 and 12. From the 11th question, we can conclude that most of the students have the chance to teach as a teacher. From the 12th question, we can conclude that most of the students cannot get out of the textbook when they teach as a teacher. To sum up, most of the students have the chance to teach as a teacher, but only a few can get out of the textbook when they do it. 
Table 5. Number and percentage of questions 6, 7 .

\begin{tabular}{ccccccccccc}
\hline \multirow{2}{*}{ Question } & \multicolumn{2}{c}{$\mathrm{A}$} & \multicolumn{2}{c}{$\mathrm{B}$} & \multicolumn{2}{c}{$\mathrm{C}$} & \multicolumn{2}{c}{$\mathrm{D}$} & \multicolumn{2}{c}{$\mathrm{E}$} \\
\cline { 2 - 10 } & No. & p.c. (\%) & No. & p.c. (\%) & No. & p.c. (\%) & No. & p.c. (\%) & No. & p.c. (\%) \\
\hline 6 & 2 & 13.33 & 6 & 40 & 6 & 40 & 0 & 0 & 1 & 6.67 \\
7 & 0 & 0 & 4 & 26.67 & 7 & 46.67 & 3 & 20 & 1 & 6.67 \\
\hline
\end{tabular}

Table 6. Number and percentage of questions $8,9,10$.

\begin{tabular}{ccccccccccc}
\hline \multirow{2}{*}{ Question } & \multicolumn{2}{c}{$\mathrm{A}$} & \multicolumn{2}{c}{$\mathrm{B}$} & \multicolumn{2}{c}{$\mathrm{C}$} & \multicolumn{2}{c}{$\mathrm{D}$} & \multicolumn{2}{c}{$\mathrm{E}$} \\
\cline { 2 - 10 } & No. & p.c. (\%) & No. & p.c. (\%) & No. & p.c. (\%) & No. & p.c. (\%) & No. & p.c. (\%) \\
\hline 8 & 0 & 0 & 2 & 13.33 & 9 & 60 & 4 & 26.67 & 0 & 0 \\
9 & 1 & 6.67 & 10 & 66.67 & 1 & 6.67 & 3 & 20 & 0 & 0 \\
10 & 2 & 13.33 & 5 & 33.33 & 8 & 53.33 & 0 & 0 & 0 & 0 \\
\hline
\end{tabular}

Table 7. Number and percentage of questions 11,12 .

\begin{tabular}{ccccccccccc}
\hline \multirow{2}{*}{ Question } & \multicolumn{2}{c}{$\mathrm{A}$} & \multicolumn{2}{c}{$\mathrm{B}$} & \multicolumn{2}{c}{$\mathrm{C}$} & \multicolumn{2}{c}{$\mathrm{D}$} & \multicolumn{2}{c}{$\mathrm{E}$} \\
\cline { 2 - 10 } & No. & p.c. (\%) & No. & p.c. (\%) & No. & p.c. (\%) & No. & p.c. (\%) & No. & p.c. (\%) \\
\hline 11 & 0 & 0 & 1 & 6.67 & 10 & 66.67 & 4 & 26.67 & 0 & 0 \\
12 & 0 & 0 & 0 & 0 & 6 & 40 & 8 & 53.33 & 1 & 6.67 \\
\hline
\end{tabular}

\subsubsection{External Causes}

1) Most of the students are serious about their homework and are satisfied with their completion.

Table 8 shows the number and percentage of questions 13, 14 and 15. From the 13 th question, we can conclude that $80 \%$ of the students are serious about their homework. From the 14th question, we can conclude that $93.33 \%$ of the students can finish their homework on time. From the 15th question, we can conclude that $93.33 \%$ of the students are satisfied with their completion. To sum up, most of the students are serious about their homework and are satisfied with their completion.

2) Most of the students read extracurricular books sometimes and most of books are related to the knowledge of professional courses.

Table 9 shows the number and percentage of questions 16 and 17. From the 16 th question, we can conclude that $86.66 \%$ of the students read extracurricular books sometimes. From the 17th question, we can conclude that most of books they read are related to the knowledge of professional courses. To sum up, we can get that most of the students read extracurricular books sometimes and most of books are related to the knowledge of professional courses.

3) For most students, the time of reviewing is not long and their review is not comprehensive.

Table 10 shows the number and percentage of questions 18, 19 and 20. From the 18 th question, we can conclude that $66.67 \%$ of the students are familiar with the knowledge of the textbooks when reviewing the specialized courses. From 
Table 8. Number and percentage of questions 13, 14, 15.

\begin{tabular}{ccccccccccc}
\hline \multirow{2}{*}{ Question } & \multicolumn{2}{c}{ A } & \multicolumn{2}{c}{ B } & \multicolumn{2}{c}{ C } & \multicolumn{2}{c}{ D } & \multicolumn{2}{c}{$\mathrm{E}$} \\
\cline { 2 - 9 } & No. & p.c. (\%) & No. & p.c. (\%) & No. & p.c. (\%) & No. & p.c. (\%) & No. & p.c. (\%) \\
\hline 13 & 0 & 0 & 12 & 80 & 2 & 13.33 & 1 & 6.67 & 0 & 0 \\
14 & 2 & 13.33 & 10 & 66.67 & 2 & 13.33 & 0 & 0 & 1 & 6.67 \\
15 & 1 & 6.67 & 0 & 0 & 8 & 53.33 & 5 & 33.33 & 1 & 6.67 \\
\hline
\end{tabular}

Table 9. Number and percentage of questions 16, 17.

\begin{tabular}{ccccccccccc}
\hline \multirow{2}{*}{ Question } & \multicolumn{2}{c}{ A } & \multicolumn{2}{c}{ B } & \multicolumn{2}{c}{ C } & \multicolumn{2}{c}{ D } & \multicolumn{2}{c}{ E } \\
\cline { 2 - 10 } & No. & p.c. (\%) & No. & p.c. (\%) & No. & p.c. (\%) & No. & p.c. (\%) & No. & p.c. (\%) \\
\hline 16 & 0 & 0 & 2 & 13.33 & 11 & 73.33 & 1 & 6.67 & 1 & 6.67 \\
17 & 5 & 33.33 & 5 & 33.33 & 2 & 13.33 & 2 & 13.33 & 1 & 6.67 \\
\hline
\end{tabular}

Table 10. Number and percentage of questions 18, 19, 20.

\begin{tabular}{ccccccccccc}
\hline \multirow{2}{*}{ Question } & \multicolumn{2}{c}{$\mathrm{A}$} & \multicolumn{2}{c}{$\mathrm{B}$} & \multicolumn{2}{c}{$\mathrm{C}$} & \multicolumn{2}{c}{$\mathrm{D}$} & \multicolumn{2}{c}{$\mathrm{E}$} \\
\cline { 2 - 10 } & No. & p.c. (\%) & No. & p.c. (\%) & No. & p.c. (\%) & No. & p.c. (\%) & No. & p.c. (\%) \\
\hline 18 & 1 & 6.67 & 4 & 26.67 & 6 & 40 & 3 & 20 & 1 & 6.67 \\
19 & 0 & 0 & 3 & 20 & 7 & 46.67 & 5 & 33.33 & 0 & 0 \\
20 & 1 & 6.67 & 8 & 53.33 & 2 & 13.33 & 1 & 6.67 & 3 & 20 \\
\hline
\end{tabular}

the 19th question, we can conclude that $80 \%$ of the students think that their review is not comprehensive. From the 20th question, we can conclude that $60 \%$ of the students review the specialized courses less than 4 hours every week. To sum up, we can get that for most students, the time of reviewing is not long and their review is not comprehensive.

4) Most of the students recognize the importance of preview but only few students will do so.

Table 11 shows the number and percentage of questions 21 and 22. From the 21 th question, we can conclude that $86.67 \%$ of the students will not preview the textbooks. From the 22th question, we can conclude that most of the students most of the students recognize the importance of preview. In conclusion, we can get that most of the students recognize the importance of preview but only few students will do so.

5) Most of the students do not recognize the importance of discussion after class and only few students will discuss after class.

Table 12 shows the number and percentage of questions 23 and 24. From the 23th question, we can conclude that $80 \%$ of the students seldom discuss with other students. From the 24th question, we can conclude that $93.33 \%$ of the students are not active in the discussion after class. In conclusion, we can get that most of the students do not recognize the importance of discussion after class and only few students will discuss after class. 
Table 11. Number and percentage of questions 21, 22.

\begin{tabular}{ccccccccccc}
\hline \multirow{2}{*}{ Question } & \multicolumn{2}{c}{ A } & \multicolumn{2}{c}{ B } & \multicolumn{2}{c}{ C } & \multicolumn{2}{c}{ D } & \multicolumn{2}{c}{ E } \\
\cline { 2 - 10 } & No. & p.c. (\%) & No. & p.c. (\%) & No. & p.c. (\%) & No. & p.c. (\%) & No. & p.c. (\%) \\
\hline 21 & 0 & 0 & 2 & 13.33 & 7 & 46.67 & 4 & 26.67 & 2 & 13.33 \\
22 & 7 & 46.67 & 7 & 46.67 & 1 & 6.67 & 0 & 0 & 0 & 0 \\
\hline
\end{tabular}

Table 12. Number and percentage of questions 23, 24.

\begin{tabular}{ccccccccccc}
\hline \multirow{2}{*}{ Question } & \multicolumn{2}{c}{$\mathrm{A}$} & \multicolumn{2}{c}{$\mathrm{B}$} & \multicolumn{2}{c}{$\mathrm{C}$} & \multicolumn{2}{c}{$\mathrm{D}$} & \multicolumn{2}{c}{$\mathrm{E}$} \\
\cline { 2 - 10 } & No. & p.c. (\%) & No. & p.c. (\%) & No. & p.c. $(\%)$ & No. & p.c. $(\%)$ & No. & p.c. (\%) \\
\hline 23 & 0 & 0 & 3 & 20 & 8 & 53.33 & 4 & 26.67 & 0 & 0 \\
24 & 1 & 6.67 & 0 & 0 & 8 & 53.33 & 6 & 40 & 0 & 0 \\
\hline
\end{tabular}

\subsection{Analysis of the Results}

From the front of the data we can draw:

For study in class, most of the students study quite hard: they are careful to listen and take notes in class, are positively in answering questions and are quite active in the discussion as well as they think seriously about classroom exercises. But there are still some difficulties such as: it is hard to understand the knowledge of professional courses, only few students can answer questions for other students and only few can get out of the textbook when they teach as a teacher.

For study after class, we can get that: most of the students are serious about their homework and they can recognize the importance of preview as well as they often read extracurricular books. But there are still some problems such as: the time of review and preview is not long and only few students will discuss af ter class.

\section{Concluding Remarks}

Based on the experimental evaluation, we arrive at the following results: 1) basic mathematics master students have high learning efficiency, but they lack enthusiasm for learning; 2) most of the students used to study under the guidance of the teacher, thus it is difficult to carry on the positive and effective study once separated from the teacher's guidance; 3 ) most of the students are limited to the knowledge of professional courses and they lack extensive study of other knowledge; and 4) most students pay more attention to the learning of book knowledge while they neglect the improvement of practical abilities.

\section{References}

[1] Fu, H. and Jia, G. (2009) Introduction to Mathematical Thinking Method. Jinan, Shandong Education Press, Jinan.

[2] Wosilait, K., Heron, P.L., Shaffer, P.S. and McDermott, L.C. (1998) Development and Assessment of a Research-Based Tutorial on Light and Shadow. American Journal of Physics, 66, 906-913. https://doi.org/10.1119/1.18988

[3] Towns, M.H. and Grant, E.R. (1997) "I Believe I Will Go Out of This Class Actually 
Knowing Something": Cooperative Learning Activities in Physical Chemistry. Journal of Research in Science Teaching, 34, 819-835. https://doi.org/10.1002/(SICI)1098-2736(199710)34:8<819::AID-TEA5>3.0.CO;2-Y

[4] McDermott, L.C. and Shaffer, P.S. (1992) Research as a Guide for Curriculum Development: An Example from Introductory Electricity. Part I: Investigation of Student Understanding. American Journal of Physics, 60, 994-1003. https://doi.org/10.1119/1.17003

[5] Briscoe, C. and LaMaster, S.U. (1991) Meaningful Learning in College Biology through Concept Mapping. The American Biology Teacher, 53, 214-219. https://doi.org/10.2307/4449272

[6] Volpe, E.P. (1984) The Shame of Science Education. Integrative and Comparative Biology, 24, 433-441. https://doi.org/10.1093/icb/24.2.433

[7] Wang, E. (2015) A Study on the Current Situation of MPCK in Mathematics Major. Shaanxi Normal University Press, Xi'an.

[8] Zhou, X. (2010) Investigation and Research on the Learning Situation of Free Normal Students in Mathematics Major. Northeast Normal University Press, Changchun.

[9] Huang, L., Xu, F. and Yuan, Y. (2012) Investigation and Analysis of the Current Situation of College Students' Mathematical Learning Habits. Heilongjiang Education, Harbin.

[10] Qi, G. and Fu, H. (2017) A Comprehensive Study on the Reason of Low Enthusiasm for Master Students Majored in Basic Mathematics. Open Journal of Social Sciences, 5, 216-226. https://doi.org/10.4236/jss.2017.54019 


\section{Appendix}

The Questionnaire on the Learning Situation for Basic Mathematics Master Students

Dear classmates:

In order to understand the learning situation of the current basic mathematics master students, we are now using an anonymous way to list some questions. Note that your answers are not treated as a basis for any assessment of you. Please read the questions carefully and choose an answer for each question. Please tick in the appropriate answer. Thank you for your cooperation.

1. For a 50-minute math class, you can usually listen to it
A. 0 to 10 minutes
B. 10 to 20 minutes
C. 20 to 30 minutes
D. 30 to 40 minutes
E. 40 to 50 minutes

2. Is it difficult for you to understand the knowledge of professional courses?
A. Very much
B. A little
C. Just so so
D. Not very difficult
E. Not difficult

3. Do you take notes on a professional course?
A. Never
B. Seldom
C. Sometimes
D. Most occasions
E. Always

4. Do you answer questions on a professional course?
A. Always
B. Most occasions
C. Sometimes
D. Seldom
E. Never

5. Can you listen to the other students carefully in the class when they answer the questions?
A. Very much
B. A little
C. Just so so
D. Not very carefully
E. Not carefully
6. Do you think seriously about the teacher's questions or assignments?
A. Very much
B. A little
C. Just so so
D. Not very seriously
E. Not seriously 


\section{Continued}

7. Are you satisfied with your classroom practice?
A. Very much
B. A little
C. Just so so
D. Not very satisfied
E. Not satisfied

8. Will you solve doubts for other students in the math class?
A. Always
B. Most occasions
C. Sometimes
D. Seldom
E. Never

9. How many students will participate in the discussion on a professional course?
A. All students
B. Most students
C. Half of the students
D. A small number of students
E. Several students

10. Do you actively participate in the discussion when you are on a professional course?
A. Very much
B. A little
C. Just so so
D. Not very actively
E. Not actively
11. Do you teach as a teacher in math class?
A. Always
B. Most occasions
C. Sometimes
D. Seldom
E. Never
12. Can you get out of the textbook when you teach as a teacher?
A. Always
B. Most occasions
C. Sometimes
D. Seldom
E. Never

13. Are you serious about your homework?
A. Very much
B. A little
C. Just so so
D. Not very serious
E. Not serious

14. Can you finish your homework on time?
A. Always
B. Most occasions
C. Sometimes
D. Seldom
E. Never 


\section{Continued}

15. Do you think your homework is done well?
A. Not well
B. Not very well
C. Not well
D. Well
E. Very well
16. Do you read extracurricular books?
A. Always
B. Most occasions
C. Sometimes
D. Seldom
E. Never

17. What kind of extracurricular materials do you often read?
A. Reference books related to specialized courses
B. Papers related to specialized courses
C. Literature books
D. Entertainment books
E. Other books

18. Are you familiar with the knowledge of the textbooks when reviewing the specialized courses?
A. Very much
B. A little
C. Just so so
D. Not very familiar
E. Not familiar

19. Do you have a comprehensive review when you review your textbook?
A. Very much
B. A little
C. Just so so
D. Not very comprehensive
E. Not comprehensive

20. How long does it take you a week there will be to review the specialized knowledge?
A. .0 to 2 hours
B. 2 to 4 hours
C. 4 to 6 hours
D. 6 to 8 hours
E. More than 8 hours

21. Can you preview the textbook?
A. Always
B. Most occasions
C. Sometimes
D. Seldom
E. Never

22. Do you think it is important to preview the textbook?
A. Very important
B. A little
C. Just so so
D. Not very important
E. Not important 


\section{Continued}

23. Do you discuss problems with classmates after class?
A. Always
B. Most occasions
C. Sometimes
D. Seldom
E. Never

24. Do you discuss the problem actively after class?
A. Very much
B. A little
C. Just so so
D. Not very actively
E. Not actively

Submit or recommend next manuscript to SCIRP and we will provide best service for you:

Accepting pre-submission inquiries through Email, Facebook, LinkedIn, Twitter, etc. A wide selection of journals (inclusive of 9 subjects, more than 200 journals)

Providing 24-hour high-quality service

User-friendly online submission system

Fair and swift peer-review system

Efficient typesetting and proofreading procedure

Display of the result of downloads and visits, as well as the number of cited articles Maximum dissemination of your research work

Submit your manuscript at: http://papersubmission.scirp.org/

Or contact jss@scirp.org 